\title{
DETERMINATION OF SEX FROM FOOT DIMENSIONS
}

\section{Bindurani M. K ${ }^{1}$, Kavyashree A. N ${ }^{*}$, Asha.K. R ${ }^{3}$, Lakshmiprabha Subhash ${ }^{4}$.}

${ }_{1,{ }^{* 2}}$ Associate professor, Department of Anatomy, Sri Siddhartha medical college, Tumkur, Karnataka, India.

${ }^{3}$ Professor, Department of Anatomy, Sri Siddhartha medical college, Tumkur, Karnataka, India.

${ }^{4}$ Professor and Head, Department of Anatomy, Sri Siddhartha medical college, Tumkur, Karnataka, India.

\section{ABSTRACT}

Introduction: Forensic podiatry deals with study of foot dimensions for human identification. The human foot shows variations in different dimensions due to genetic and environmental factors.

Aims and Objectives: The aim of our study was to determine the correlation of various measurements of the feet with sex and to evaluate logistic regression equations to predict sex of a person by using dimensions of feet.

Materials and Methods: The study was conducted on 341 students, aged between 18-22 years from Sri Siddhartha university, Tumkur, Karnataka. After taking their consent Foot length, foot breadth and Bi malleolar breadth were recorded and subjected for statistical analysis.

Results: The mean values of Foot length, Foot breadth, and Bimalleolar breadth were significantly higher in males than females. The average foot index in males and females were 44.91 and 42.63 respectively. Logistic regression equations to determine sex of a person by using different parameters of foot dimensions were formulated. Foot length showed least correlation with sex at R2 0.038 whereas Foot breadth showed highest correlation with sex at R2 0.4 . Prediction of sex with multiple logistic regression equations showed better accuracy than than regression equations of individual parameters.

Conclusion: Foot length, Foot breadth, Bimalleolar breadth and foot index are higher in males compared to females. This proves sexual dimorphism of foot dimensions. Foot length showed least correlation and foot breadth highest correlation with sex. Prediction of sex with multiple logistic regression equations was better than with regression equations of individual parameters.

KEY WORDS: Sex determination, Foot dimensions, Foot length, Foot breadth, Bimalleolar breadth, Foot index.

Address for Correspondence: Dr. Kavyashree A. N, Associate professor, Department of Anatomy, Sri Siddhartha medical college, Tumkur. Pin code. 572107, Karnataka, India.

E-Mail: kavyashreean@gmail.com

\begin{tabular}{|c|c|c|}
\hline \multicolumn{3}{|c|}{ Access this Article online } \\
\hline \multirow{2}{*}{ Quick Response code } & \multicolumn{2}{|c|}{$\begin{array}{l}\text { Web site: International Journal of Anatomy and Research } \\
\qquad \text { ISSN 2321-4287 } \\
\text { www.ijmhr.org/ijar.htm }\end{array}$} \\
\hline & $\begin{array}{l}\text { Received: } 19 \text { Sep } 2017 \\
\text { Peer Review: } 20 \text { Sep } 2017 \\
\text { Revised: None }\end{array}$ & $\begin{array}{l}\text { Accepted: } 20 \text { Oct } 2017 \\
\text { Published (O): } 01 \text { Dec } 2017 \\
\text { Published (P): } 01 \text { Dec } 2017\end{array}$ \\
\hline
\end{tabular}

\section{INTRODUCTION}

Anthropometry as adopted by medical scientistis is described as a technique of expressing the form of human body quantitatively as it is the systematic collection and correlation of measurement of the humanbody [1] . It is highly objective and reliable in the hands of trained anthropometrists [2]. The significance of somatometry, cephalometry, craniometry and osteometry in the identification of human remains have been described by a new term, 'forensic anthropometry'. Forensic podiatry deals with the study of foot dimensions for human identification. 
The human foot, the foundation of bipedal locomotion, is a highly complex multi bone structure with 26 bones and numerous articulation [3]. It shows variations in different dimensions due to genetic and environmental factors. The morphology of human feet is greatly influenced by combined effects of heredity and living style. These determine the size and shape of the feet and footprints and thereby making those unique data to establish human identity [4].

The study of the human foot in forensic identification has been emphasized because of the increased likelihood of retaining the foot (often protected by the shoes) in the case of mass disasters, terrorists' attacks, wars, explosions, and high-impact transportation accidents [5].

Quantitative analysis of foot anthropometry is important to the study of ergon metrics, orthotics designing of foot devices [6].

The study of foot dimensions is significant clinically. Schultz et al reported that many girls with Rett Syndrome had small feet for height [7]. Rodier et al observed that children with autism had smaller feet compared with the control group [8].

The identification of a deceased person is the mainstay of forensic analysis. Therefore, the primary aim for any forensic anthropologist is to reconstruct an osteobiography consisting of a set of biological attributes, for example, sex, stature, and age [9].

Very few studies have attempted to generate equations to determine sex of a person. The aim of our study was to determine the correlation of various measurements of the feet with sex and to evaluate logistic regression equations to predict sex of a person by using dimensions of feet. The data presented in this study is useful for forensic science researchers, investigators and legal experts to aid in sex determination of a person.

\section{MATERIALS AND METHODS}

The present study was undertaken amongst 341 students, aged between 18-22 years from Sri Siddhartha university, Tumkur, Karnataka . In our study, the sample included only the students above the age of 18 years, as above this age, most people attain their maximum growth and therefore their maximum foot length and breadth [10]. Ethical clearance was obtained from the ethical clearance committee and prior informed consent of the study was obtained from all the subjects in writing. Basic Sociodemographic indices like age, sex and region to which they belonged were taken. The subjects with any apparent physical foot anomalies, inflammation, surgery, trauma, orthopedic deformities, metabolic or developmental disorders were excluded. The foot dimensions were measured with foot placed on a horizontal flat surface while the subject was standing erect in anatomical position and bare-footed. The following measurements were taken.

Foot Length (FL): Foot length was measured as a direct distance from the most prominent point of the back of the heel (pternion) to the most distal part of longest toe (acropodian). The caliper was horizontally placed along the medial border of the foot. The fixed part of the outer jaw of the caliper was applied to the pternion and the mobile part of the outer jaw was approximated to the acropodian and measurements were taken. In the same way, the measurements were taken on the other side.

Foot Breadth (FB): It is obtained as a distance between metatarsal tibiale (medial margins of the head of the first metatarsal) and metatarsal fibulare, (the lateral margin of the head of the fifth metatarsal) using sliding caliper.

Bimalleolar breadth: It was obtained as distance between the most medial projection of medial malleolus and the most lateral projection of lateral malleolus using sliding caliper [11]. The measurements were recorded in centimeters to the nearest $0.1 \mathrm{~cm}$. The measurements were taken at a fixed time to eliminate any diurnal variation and by single observer in order to avoid inter-observer bias.

The foot index was calculated by the formula

Foot Index = Foot breadth / Foot length $x 100$

The data were collected, and analysed by Statistical package for social sciences. (SPSS)

\section{RESULTS AND OBSERVATIONS}

In the present study anthropometry of foot were studied in 341 subjects and results were recorded as follows 
Table 1: Descriptive statistics for Foot length, Foot breadth, and Foot bimalleolar breadth in both sex and for right and left side.

\begin{tabular}{|c|c|c|c|c|c|c|c|c|c|c|c|c|}
\hline \multirow[b]{3}{*}{ Side } & \multicolumn{4}{|c|}{ Foot length $(\mathrm{cm})$} & \multicolumn{4}{|c|}{ Foot breadth $(\mathrm{cm})$} & \multicolumn{4}{|c|}{ Bimalleol breadth $(\mathrm{cm})$} \\
\hline & \multicolumn{2}{|c|}{ female $(n=181)$} & \multicolumn{2}{|c|}{ male $(n=160)$} & \multicolumn{2}{|c|}{ female $(n=181)$} & \multicolumn{2}{|c|}{ male $(n=160)$} & \multicolumn{2}{|c|}{ female $(n=181)$} & \multicolumn{2}{|c|}{ male $(n=160)$} \\
\hline & Rt & Lt & Rt & Lt & Rt & Lt & Rt & Lt & Rt & Lt & Rt & Lt \\
\hline mean & 20.32 & 20.33 & 21.55 & 21.57 & 8.54 & 8.48 & 9.37 & 9.37 & 6.35 & 6.35 & 7.08 & 7.06 \\
\hline Standard Error & 0.18 & 0.18 & 0.29 & 0.29 & 0.05 & 0.05 & 0.06 & 0.05 & 0.05 & 0.05 & 0.05 & 0.05 \\
\hline Standard Deviation & 2.41 & 2.48 & 3.61 & 3.66 & 0.68 & 0.68 & 0.7 & 0.68 & 0.72 & 0.72 & 0.66 & 0.69 \\
\hline Minimum & 17 & 17 & 17.2 & 17.2 & 6.1 & 6 & 6.2 & 6.6 & 4.5 & 4.4 & 4.5 & 4.5 \\
\hline Maximum & 25.5 & 26.5 & 28.4 & 28.3 & 10.3 & 10.6 & 11 & 11 & 9.1 & 9.1 & 9.2 & 9.5 \\
\hline $\mathrm{p}$ value $\mathrm{b} / \mathrm{w}$ sides & \multicolumn{2}{|c|}{0.48} & \multicolumn{2}{|c|}{0.22} & \multicolumn{2}{|c|}{0.47} & \multicolumn{2}{|c|}{0.48} & \multicolumn{2}{|c|}{0.5} & \multicolumn{2}{|c|}{0.4} \\
\hline Average foot length & \multicolumn{2}{|c|}{20.32} & \multicolumn{2}{|c|}{21.56} & & & \multicolumn{2}{|c|}{9.37} & \multicolumn{2}{|c|}{6.35} & \multicolumn{2}{|c|}{7.07} \\
\hline$p$ value $b / w$ sex & \multicolumn{4}{|c|}{$<0.001 *$} & \multicolumn{4}{|c|}{$<0.001^{*}$} & \multicolumn{4}{|c|}{$<0.001^{*}$} \\
\hline
\end{tabular}

*Student $t$ test $-\mathrm{p}$ value of $<0.05$ indicates significance difference between groups

The mean values of Foot length, Foot breadth , and Bimalleolar breadth were significantly higher in males than females. These sex differences were statistically significant as indicated by Student $t$ test ( $p$ value $<0.05$ ).

However there were no bilateral statistical differences in all these parameters in both the sexes.

Table 2: Foot index for average foot dimensions in both sexes.

\begin{tabular}{|c|c|c|c|c|}
\hline Sex & Side & $\begin{array}{c}\text { Foot } \\
\text { Length } \\
(\mathrm{cm})\end{array}$ & $\begin{array}{c}\text { Foot } \\
\text { Breadth } \\
(\mathbf{c m})\end{array}$ & Foot Index \\
\hline \multirow{2}{*}{ Female } & Right & 20.32 & 8.54 & 42.03 \\
\cline { 2 - 5 } & Left & 20.33 & 8.48 & 42.51 \\
\hline \multirow{2}{*}{ Male } & Right & 21.55 & 9.37 & 43.48 \\
\cline { 2 - 5 } & left & 21.57 & 9.37 & 43.44 \\
\hline
\end{tabular}

Table 3: Descriptive statistics for Foot index in sex and side

\begin{tabular}{|c|c|c|c|c|}
\hline & \multicolumn{2}{|c|}{ Female } & \multicolumn{2}{c|}{ Male } \\
\hline & Rt & Lt & Rt & Lt \\
\hline Mean & 42.75 & 42.49 & 44.92 & 44.91 \\
\hline Standard Error & 0.52 & 0.52 & 0.73 & 0.73 \\
\hline Standard Deviation & 7.04 & 7.05 & 9.23 & 9.2 \\
\hline Minimum & 27.48 & 26.67 & 26.96 & 27.97 \\
\hline Maximum & 57.71 & 57.63 & 62.64 & 62.64 \\
\hline Average Foot Index & \multicolumn{3}{|c|}{42.63} & \multicolumn{3}{c|}{44.91} \\
\hline Student t test p value & \multicolumn{4}{|c|}{$<0.01^{*}$} \\
\hline
\end{tabular}

There were no significant difference between right and left side foot indices in both sexes. The mean Foot index in males was significantly higher than that in females $(p<0.001)$. The average foot index in males and females were 44.91 and 42.63 respectively.

Table 4 depicts logistic regression equations to determine sex of a person by using different parameters of foot dimensions. Foot length showed least correlation with sex at R2 0.038. The correlation of Foot breadth with sex was best with R2 of 0.4 . Prediction of sex with multiple logistic regression equations was better than with regression equations of individual parameters.

Table 4: Correlation coefficient and logistic regression equations for sex determination from different parameters of foot dimensions.

\begin{tabular}{|c|c|c|c|}
\hline S. No & Logistic regression equation & $\begin{array}{c}\text { Correct average } \\
\text { prediction percentage }\end{array}$ & $\mathrm{R}^{2}$ \\
\hline 1 & $\mathrm{~S}=-2.33+0.106(\mathrm{FL})$ & $62.28 \%$ & 0.038 \\
\hline 2 & $\mathrm{~S}=-18.084+2.0045(\mathrm{FB})$ & $73.68 \%$ & 0.4 \\
\hline 3 & $\mathrm{~S}=-10.193+1.499(\mathrm{BB})$ & $72.51 \%$ & 0.282 \\
\hline 4 & $\mathrm{~S}=-25.69+0.235(\mathrm{FL})+2.31(\mathrm{FB})$ & $78.36 \%$ & 0.474 \\
\hline 5 & $S=-16.015+1.73(\mathrm{BB})+0.2029(\mathrm{FL})$ & $76.90 \%$ & 0.356 \\
\hline 6 & $S=-18.65+1.528(\mathrm{FB})+0.721(\mathrm{BB})$ & $76.02 \%$ & 0.423 \\
\hline 7 & $S=-27.05+0.05(\mathrm{FL})+1.75(\mathrm{FB})+0.89(\mathrm{BB})$ & $79.53 \%$ & 0.504 \\
\hline
\end{tabular}

cut off for all equations is 0.5 scores $<0.5$ indicate male, $>0.5$ indicate female

$\mathrm{FL}-$ Foot length

FB-Foot breadth

BB-Bimalleolar breadth

S-Sex

\section{DISCUSSION}

The human foot, the foundation for bipedal locomotion, is a complex adaptation that evolved through extensive remodeling of the hind appendage of the human arboreal primate forebears [12]. The normal human foot shows great individual variation in length, breadth in males and females [13]. Sex determination from Foot dimensions has major role in personal identification.

The mean values of Foot length, foot breadth, and Bimalleolar breadth were significantly larger in males than in females.( $p$ value ,0.001). This 
goes in hand with earlier studies and proves sexual dimorphism in foot length, foot breadth $[2,10,14]$ and bimalleolar breadth. $[15,16]$.

In the present study males had an average foot length of $1.24 \mathrm{~cm}$ and foot breadth of $0.86 \mathrm{~cm}$ more than that in females. Bimalleolar breadth was found to be $0.72 \mathrm{~cm}$ more in males than in females. Longer and broader foot in males could be due to heavier bone structure of male skeleton causing weight bearing on the male foot compared to females [17].

In our study there were no bilateral differences in all the foot dimensions in both sexes. In a study on adult Nigerian population Bob-Manuel observed that right sided foot was longer and broader than left foot. [18]. In a study on Haryanvi jat population, foot length and Foot breadth were higher on right side in males whereas these parameters were higher on left side in females.[12]. These variations could be due to differences in community and environmental factors.

Foot index in the present study were 44.91 and 42.63 for males and females respectively. This goes in hand with earlier studies who observed that Foot index is more in males than in females. $[14,18]$. However few studies reported higher foot index in females than in males. $[10,19]$.

Our study is comparable with Study by Sen on Bengali Rajbanshi population on 175 males and 175 females who reported a foot index of 41.3 in males and 40.5 in females on both right and left side [20]. A study on of Nigerian population observed higher foot index as in our study [19].

A study by Danborno B on Nigerian population [14] and Singla on Haryanvi and north Indian population [21] reported lower foot index than our study. These variations could be due to fact that anatomic structures of foot shows ethnical and regional variations owing to genetic background, climatic factors, physical activities, socio-economic status, nutritional conditions and practice of using different footwear. $[15,22,23]$.

Sexual dimorphism made us to derive logic regression equations by using different parameters of foot dimensions to determine the sex of a person. . Foot length showed least individual correlation with sex at R2 0.038 and prediction rate of $62.28 \%$. where as Foot breadth showed highest individual correlation with sex at R2 of 0.4 . and prediction rate of $73.68 \%$. In a study by Koutilya, Foot length showed least correlation and foot breadth at heel highest correlation with sex [24]. In an another study, Ozden et al reported that Foot length had better correlation with sex than foot width [25].

In our study prediction of sex with multiple logistic regression equations were better than with regression equations of individual parameters. Sex was correlated best when a combination of average foot length, average foot breadth and average bimalleolar breadth were considered. These findings were similar to the observations recorded by Koutilya [24] .

\section{CONCLUSION}

Foot length ,Foot breadth, Bimalleolar breadth and foot index are higher in males compared to females. This proves sexual dimorphism of foot dimensions. Foot length showed least correlation and foot breadth highest correlation with sex. Prediction of sex with multiple logistic regression equations was better than with regression equations of individual parameters. This study serves as useful tool for forensic science researchers, investigators and legal experts to aid in sex determination of a person.

\section{Conflicts of Interests: None}

\section{REFERENCES}

[1]. Wilbur AK; The utility of hand and foot bones for the determination of sex and the estimation of stature in a prehistoric population from westcentrallllinois. International Journal of Osteoarchaeology, 1998;8(3):180-191.

[2]. Krishan K, Sharma A. Estimation of Stature from Dimensions of Hands and Feet in a North Indian Population. Journal Forensic Legal Med. 2007;14:327-332.

[3]. Dupartius A, Dupartius CW, Casey AE. Physical anthropology of young adult females in Slieve Loughter,South West Island. AMJ Phys Anthropol. 1972;37:435.

[4]. Rao NG, Kotian MS. Footprint ratio- a clue for establishing sex indentity. J Ind Acad Forensic Med. 1990; (12):51-56

[5]. Krishan. Determination of stature from foot and its segments in a North Indian Population. American journal of Forensic medicine and pathology. 2008;29(4):297-303. 
[6]. Shaifaly Medan Rustagi, Patnaik W Gopichand, Sanjeev Thakyal. A Study of Foot Anthropometry in Right Footed Indian Population. Medicolegal - update, 2013; (1)130-35

[7]. Schultz R, Glaze D. Motilk, Hobert D, Percy A. Hand and foot growth Failure in Rett Syndrome. 1998; 13(2): 71-74.

[8]. Rodier P M, Bryson SE, Welsh JP. Minor malformation and physical measurements in autism data from Nova Scotia Teratology. 1997;55(5):319-325.

[9]. D. A. Komar and J. E. Buikstra, Forensic Anthropology: ContemporaryTheory and Practice, University Press, NewYork, NY, USA, 2008

[10]. Agnihotri AK, Shukla S, Purwar B. Determination of sex from the foot measurements. The Internet J Forensic Sci .2007: 2:1.

[11]. Singh IP and Bhasin MK (1968) Anthropometry. A Laboratory manual of biological anthropology. Delhi: Kamla Raj Enterprises: pp1-35.

[12]. Walia S, Shankar modi B, Puri N. Sexual dimorphism from foot dimensions and foot prints in Haryanvi jat population._Int J Anat.Res. 2016; 4(1):2142-47.

[13]. Snell Richards - Clinical Anatomy for medical students 6 th ed. London:Lippincott Williams and Wilkins;1993 . p.468- 70 (S)

[14]. Danborno B,Flukpu A. Sexual dimorphism in hand and foot length, Indices, statureratio and Relationship to height in Nigerians.The internat journal of Forensic science.2008;3(1):379-383.

[15]. A. A. Ahmed. Estimation of sex from the lower limb measurements of Sudanese adults. Forensic Science International.2013;299(1-3):169.e1-169.e7.

[16]. Ekezie Jervas. Foot Anthropometry: A Forensic and Prosthetic Application. International Journal of Science and Research (IJSR); 2015;4(6):738-746.

[17]. Krishan K, Kanchan T, Abhilasha S. Multiplication factor versus regression analysis in stature estimation from hand and foot dimensions. Journal of Forensic and Legal Medicine. 2012;19(1):211-214.

[18]. I Bob-Manuel, B Didia. Sexual Dimorphism In Foot Dimensions Among Adult Nigerians. The Internet Journal of Biological Anthropology. 2008;3(1).
[19]. S.M. Chiroma, J. Philip, O.O Attah, N.I Dibal. Comparison of the Foot Height, Length, Breadth and Foot Types between Males and Females Ga'anda People, Adamawa, Nigeria. IOSR Journal of Dental and Medical Sciences. 2015; (14)8;89-93.

[20]. Sen J, Kanchan T, Ghosh S. Sex estimation from foot dimensions in an Indigenous Indian population. J Forensic Sci 2011;56:S1, doi : 10.1111/j.15564029.2010.01578.x

[21]. Singla R, Bedi M, Biswas M. Sex estimation from foot anthropometry in Haryanvi Jats and North Indian mixed population. J Punjab Acad Forensic MedToxicol. 2012;12(1):13-6.

[22]. D. T. Case and A. H. Ross. Sex determination from hand and foot bone lengths. Journal of Forensic Sciences. 2007;52(2):264-270.

[23]. G. Zeybek, I. Ergur, and Z. Demiroglu, "Stature and gender estimation using foot measurements," Forensic Science International, vol. 181, no. 1-3, pp. 54.e1-54.e5, 2008.

[24]. Kautilta V,Bodkha P, Poothanathan P. "Determination of Stature and Sex from anthropometry of foot among south Indians". Interenational journal of Review in Life Sciences. 2013;3(2):22-26.

[25]. Ozden H, yaseminB, Canan D, Akin T, Mehmet E. "Stature and sex estimation using foot and shoe dimensions" . Forensic science International. 2005;141(1):181-184.

How to cite this article:

Bindurani M. K, Kavyashree A. N, Asha.K. R, Lakshmiprabha Subhash. DETERMINATION OF SEX FROM FOOT DIMENSIONS.Int J Anat Res 2017;5(4.3):4702-4706. DOI: 10.16965/ijar.2017.450 